\title{
Producer survey of bird-livestock interactions in commercial dairies
}

\author{
S. A. Shwiff, ${ }^{\star}$ J. C. Carlson, ${ }^{\star 1}$ J. H. Glass,† J. Suckow,‡ M. S. Lowney,§ K. M. Moxcey, ${ }^{\star}$ B. Larson, ${ }^{\star}$ \\ and G. M. Linz\# \\ *US Department of Agriculture, Animal and Plant Health Inspection Service, Wildlife Services, National Wildlife Research Center, \\ 4101 LaPorte Avenue, Fort Collins, CO 80521 \\ tUS Department of Agriculture, Animal and Plant Health Inspection Service, Pennsylvania Wildlife Services, PO Box 60827, \\ Harrisburg, PA 17106 \\ fUS Department of Agriculture, Animal and Plant Health Inspection Service, Wisconsin Wildlife Services, 732 Lois Drive, Sun Prairie, WI 53590 \\ §US Department of Agriculture, Animal and Plant Health Inspection Service, New York Wildlife Services, 1930 Route 9, Castleton, NY 12033 \\ \#US Department of Agriculture, Animal and Plant Health Inspection Service, Wildlife Services, National Wildlife Research Center, \\ 2110 Miriam Circle, Suite B, Bismarck, ND 58501-2502
}

\section{ABSTRACT}

The objective of this producer survey was to identify and estimate damage caused by bird-livestock interactions in commercial dairies. The interactions between birds and livestock have previously been implicated in causing economic damage while contributing to the environmental dissemination of microorganisms pathogenic to livestock and humans. Very little research exists to help producers understand what bird species use dairies, why they use dairies, or the scope and nature of damage created as a result of bird-livestock interactions. To better characterize these interactions, we surveyed dairy operators within Pennsylvania, New York, and Wisconsin. Survey results suggest that the most common and destructive bird species found on commercial dairies are invasive to North America, and their use of dairies is associated with the loss of cattle feed, increased operating costs, and an increase in dairies self-reporting Salmonella spp. and Mycobacterium avium ssp. paratuberculosis. Cattle feed loss estimates generated from this survey were used to parameterize an input-output (IO) economic model using data from 10 counties in the state of Pennsylvania (Bedford, Berks, Blair, Bradford, Chester, Cumberland, Franklin, Lancaster, Lebanon, and Somerset). This IO model allowed us to estimate direct, indirect, and induced economic effects of feed loss from bird damage to dairies within these counties. The IO model output suggests that feed loss costs Pennsylvania between $\$ 4.11$ and $\$ 12.08$ million (mean $\$ 10.6$ million) in total economic damage, with approximately 43 to 128 jobs (mean 112) forgone statewide in 2009.

Key words: dairy cow, economic damage, bird, disease

Received December 1, 2011.

Accepted July 22, 2012.

${ }^{1}$ Corresponding author: james.c.carlson@aphis.usda.gov

\section{INTRODUCTION}

The interactions between wildlife species and livestock have been implicated in causing economic damage, veterinary health hazards, and public health risks (Glahn and Stone, 1984; Pedersen and Clark, 2007; LeJeune et al., 2008). The existing literature provides few insights into how, when, or where bird-livestock interactions create problems for dairies. The data that do exist suggest that wild birds cause damage through the consumption of livestock feed (White et al., 1985; Depenbusch et al., 2011), and this may contribute to microbial contamination of the cattle feed and water supplies (Carlson et al., 2011a,b).

According to Twedt and Glahn (1982), feed consumed by birds appears to be the most important bird-related problem faced by livestock producers. Estimates of cattle feed loss attributable to bird use of US dairies do not exist, but Pimentel et al. (2005) estimated that European starlings alone may cause US\$800 million in damage to agriculture annually. Glahn and Otis (1981) estimated that 1,000 starlings can consume up to $630 \mathrm{lb}$ $(286 \mathrm{~kg})$ of cattle feed every hour spent foraging on facilities. Last, if feed consumption by birds occurs at the feed bunk, then removal of high-energy feed ingredients by starlings may reduce BW gain and milk production, and these losses may be economically significant to producers (Feare, 1984).

Information characterizing disease risks attributable to bird use of dairies is limited. The information that does exist suggests that wild birds carry microorganisms that are pathogenic to livestock and humans (Hubálek, 2004). Serotypes of Salmonella enterica, known to cause infections in livestock and humans, have been isolated from asymptomatic house sparrows (Passer domesticus), brown-headed cowbirds (Molothrus ater), Brewer's blackbirds (Euphagus cyanocephalus), European starlings (Sturnus vulgaris), house finches (Carpodacus mexicanus), red-winged blackbirds (Agelaius phoeniceus), and rock pigeons (Columba livia) captured 
Table 1. Number of surveys received, herd size, and method of penning among respondents in the analysis of bird damage to dairies within Pennsylvania, New York, and Wisconsin in 2009

\begin{tabular}{|c|c|c|c|c|c|c|c|}
\hline \multirow[b]{2}{*}{ State } & \multirow[b]{2}{*}{ Dairies $^{1}$} & \multicolumn{3}{|c|}{ Herd size ${ }^{2}$} & \multicolumn{3}{|c|}{ Animal housing } \\
\hline & & $<500$ & 500 to 1,000 & $>1,000$ & Free stall & Tie stall & Paddocks \\
\hline Pennsylvania & 220 & 212 & 7 & 1 & 105 & 111 & 4 \\
\hline New York & 119 & 97 & 9 & 13 & 62 & 54 & 3 \\
\hline Wisconsin & 60 & 31 & 24 & 5 & 53 & 5 & 2 \\
\hline
\end{tabular}

${ }^{1}$ Dairies denotes the number of respondents within each state used in the analyses of bird damage to dairies.

${ }^{2}$ Herd size denotes the total number of cattle, including dry cows and first-year heifers.

within dairies, suggesting that transmission across species is possible (Kirk et al., 2002). Pedersen et al. (2006) isolated the same serotypes of $S$. enterica from rock pigeons, cattle feed, water troughs, and cattle feces collected within dairies, implicating pigeons as a potential source of $S$. enterica contamination within dairies. $M y$ cobacterium avium ssp. paratuberculosis (MAP), the causative agent of Johne's disease in cattle, has been isolated from European starlings and house sparrows trapped on dairies in Wisconsin (Corn et al., 2005). Currently, it is unknown whether carriage of microorganisms by birds using dairies causes disease in milk cows or reduces the productive capacity of dairies.

An assessment of bird damage in US dairies does not exist. This information could help dairies identify high-risk bird species, areas of economic damage, and cost-effective management solutions. An assessment is also needed to identify the focus of future research efforts to address the economic, veterinary health, and public health risks associated with bird use of dairies. In an effort to achieve these goals, we surveyed milk producers within Pennsylvania, Wisconsin, and New York to (1) identify and rank bird species using dairies; (2) characterize where and how birds cause damage in dairies; and (3) begin to estimate the economic costs of bird damage in US dairies. To achieve this last objective, survey results from Pennsylvania were used to parameterize an input-output (IO) economic model, IMPLAN (MIG Inc., Hudson, WI), which enabled us to estimate region-wide economic impacts associated with bird damage to commercial dairies.

\section{MATERIALS AND METHODS}

The 2009 Bird Damage to Dairy Operations Survey gathered information from commercial dairies within the states of Wisconsin, New York, and Pennsylvania. These states were selected because they requested assistance with bird problems and because they are the second, third, and fourth largest milk-producing states in the United States, respectively. Participation in the survey was voluntary, and names and addresses of dairies were excluded to guarantee respondent anonymity.
The survey consisted of 21 questions related to facility operations, dairy productivity, and bird ecology. Here, we report results only for commercial dairies with $\geq 50$ milk cows. Facilities that did not produce any milk products, such as beef feedlots and calving operations, were excluded from the analysis. We distributed 3,700 surveys: 700 in Wisconsin, 1,000 in New York, and 2,000 in Pennsylvania. The response rate was $10.8 \%$ (Table 1).

\section{Estimating Bird Numbers, Species, and Damage}

Estimating Bird Numbers. Dairy operators were asked whether they had experienced any bird damage to their dairies in 2009. Respondents who checked "no" were classified as having zero birds per day on their facility. Respondents who answered "yes" were asked to identify the peak number of birds per day that were on their dairies in 2009. All respondents were grouped into 4 bird abundance categories: 0 birds; 1 to 1,000 birds; 1,001 to 10,000 birds; and >10,000 birds. We used categorical rather than numerical data for bird abundance because of the difficulty in accurately estimating flock size on dairies. We found, based on previous attempts to estimate bird numbers on livestock facilities (Carlson et al., 2011a,b), that producers could reliably estimate flock sizes within these general bird abundance categories.

Identifying Bird Species. Among the respondents who answered "yes" to bird damage on dairies, additional information related to bird ecology was obtained. Dairy operators were asked to identify the bird species present on their dairies and rank these species from most common (1) to least common (8). To help dairy operators positively identify species, we provided pictures of 6 species commonly found on livestock facilities: European starling, red-winged blackbird, house sparrow, rock pigeon, brown-headed cowbird, and American crow (Corvus brachyrhynchos). Dairy operators were also provided the option of writing in and ranking other species or unknown species.

Identifying Bird Damage. Among dairies reporting bird damage, we asked producers to estimate the 
percentage of cattle feed consumed by birds and the percentage of cattle feed spoiled by birds. We asked dairy operators reporting bird damage to identify methods used to control bird damage on their dairies and the efficacy and cost associated with each control method. We asked dairy operators reporting bird damage to provide seasonal rank estimates $(1=$ greatest, 4 = least) for bird abundance, bird fecal pollution, bird-related feed loss, and bird control costs. Seasonal estimates were separated by the dates of January 1 to March 31, April 1 to June 30, July 1 to September 30, and October 1 to December 31 .

\section{Estimating Dairy Productivity, Operating Costs, and Herd Health}

Estimating Dairy Productivity. We asked all dairies to provide the total number of dairy cows on their facilities, including dry cows and first-year heifers. We also asked dairy operators to provide the total number of cows milked per day. We assumed the number being milked represented the percentage of the total herd in production on any given day in 2009.

We asked facilities to provide the total pounds of milk produced on their dairies; these numbers were divided by 100 to estimate hundredweight (cwt) of milk produced in 2009. Total pounds of milk produced on dairies was also divided by the number of cows currently being milked to estimate pounds of milk per cow per year in 2009. We asked dairy operators to provide the total pounds of butterfat produced on their dairies. These numbers were divided by the number of cows currently being milked to estimate the pounds of butterfat produced per cow per year in 2009. Dairy operations were also asked to provide the average protein content of their milk.

Estimating Operating Costs. We asked dairies to provide the annual costs of feeding cattle. These numbers were divided by cwt to estimate feed costs per cwt of milk produced in 2009. Annual costs of feeding cattle were also multiplied by the percentage of feed lost to birds. Feed lost to birds consisted of consumption plus spoilage estimates. These data were used to estimate the cost of feed loss by bird abundance category. We asked all dairies to provide their annual veterinary care costs. These costs were divided by the total number of cows, including dry cows and first-year heifers, to estimate veterinary care costs per cow per year in 2009.

Estimating Herd Health and Animal Housing. We asked dairy operators to report the occurrence of MAP and Salmonella spp. in their herds. No diagnostic samples were collected. All MAP and Salmonella spp. data reflect self-reporting (presence or absence) within herds by dairy operators. We asked dairy operators to report the average SCC of their bulk tank milk. We asked dairy operators to tell us what type of animal housing they used: tie stalls, free stalls, or group housed in paddocks. We also provided the option for dairy operators to write in other methods of housing.

\section{Data Analysis}

Survey Results. All feed, veterinary, animal health, and production data were assessed for associations with bird abundance estimates. Analyses of dairy production and veterinary cost data included herd size as a model covariate.

We used a random stratified sampling design to analyze all bird damage data. All bird damage data were analyzed using SURVEYREG and SURVEYLOGISTIC procedures in SAS 9.2 (SAS Institute Inc., Cary, NC). The data were divided into 3 strata (state of origin), and a random sample of all dairies within each state was drawn from National Agricultural Statistical Service databases. Taylor series approximations were used to calculate variance estimates. Data from different states were weighted using a finite population correction, where weights were the inverse of the probability of a dairy being randomly selected for inclusion in the study. Within all bird damage analyses, bird abundance estimates were the explanatory variable.

All feed and veterinary cost data were analyzed using ANOVA in SURVEYREG. For all models, the response variable was cost in US dollars $(\$)$. Milk production data were analyzed using ANOVA. The response variable was pounds of milk produced per cow per year. Percentage of feed loss, percentage of feed spoilage, and percentage of protein in milk were analyzed using ANOVA. Percentage of data were transformed using the arcsine square root, logistic, log, and square root transformations. All linear transformations of percentage of data were assessed using residual versus predicted plots. We selected the square root transformation for analysis of all models based on residual output. The response variable was square root transformed percentage data. Untransformed data were used to produce figures and mean estimates of percentage data by bird abundance categories.

Self-reported Salmonella spp. and MAP data were analyzed using logistic regression in SURVEYLOGISTIC. For both models, the response variable was self-reported (presence or absence) Salmonella spp. and MAP on dairies. We estimated model fit using the gamma statistic, which is a measure of the association between the predicted probabilities and observed responses. Odds ratios (OR) and their 95\% confidence intervals were estimated for both the Salmonella and MAP models. Odds ratios were a measure of effect size, 
which represented the odds of dairies reporting Salmonella spp. or MAP in their herds by bird abundance categories.

Animal housing data were analyzed using an ordinal model for multinomial data with PROC GENMOD in SAS version 9.2. Bird abundance estimates were the response variable, and type of animal penning was the explanatory variable. Odds ratios and their 95\% confidence intervals were estimated for each animal penning method. Odds ratios were a measure of effect size, which represented the odds of birds occupying facilities that used free stalls, tie stalls, or paddocks to house cattle.

We were unable to produce butterfat and SCC data because inconsistencies were found in how dairies reported this information. Butterfat was reported in pounds and as percentage of milk. Transformed butterfat data showed signs of heteroscedasticity and could not be analyzed using ANOVA within SURVEYREG. Many SCC responses were not averaged over 2009; some dairies provided only their most recent counts. Consequently, we felt butterfat and SCC data were unreliable, and they were omitted from this analysis.

IMPLAN Analysis. To examine the potential economic effects associated with bird damage in dairies, a range of estimates were modeled using the IMPLAN IO modeling program. This model can estimate incremental regional effects as economic sector (e.g., agricultural, manufacturing, and industrial) change activity through multiplier relationships based on IO tables that measure production linkages in the economy. Multipliers measure the change in the level of regional value added or output and employment associated with a unit change in direct effects (e.g., producer income) of a particular economic sector. Many factors can play a role in determining how dairies ultimately deal with potential feed losses as a result of bird damage. For example, some dairies may have enough excess feed on hand to simply push more feed to the animals, potentially compensating for any lost feed resulting from bird damage. Other dairies however, may be forced to purchase additional feed or supplements to compensate for losses. If a producer purchases or grows additional feed to account for ruined or consumed dairy rations from birds, then the producer is forgoing the purchase or production of other goods, which can be seen as the "opportunity costs" associated with bird damage to feed at dairy facilities.

Bird damage estimates were obtained from the survey results. The potential opportunity cost is modeled as lost producer income (the direct effect) as a result of the producer purchasing additional feed and supplements to have on hand to compensate for feed loss to birds. Additionally, the businesses that rely on the dairy producer's income would receive less revenue (the indirect effects). These secondary effects, consisting of the indirect and induced effects, can be estimated as they ripple through the regional economy. Previous attempts at estimating bird damage have been limited to direct economic impacts to dairies (Besser et al., 1968; Lee, 1987; Depenbusch et al., 2011). Our IO model allowed us to estimate indirect and induced economic impacts, enabling us to produce a more comprehensive assessment of bird damage to dairies.

Using IMPLAN, we estimated a range of potential economic impacts to the state of Pennsylvania created from bird damage within 10 counties (e.g., Bedford, Berks, Blair, Bradford, Chester, Cumberland, Franklin, Lancaster, Lebanon, and Somerset). Our stratified weighted data from all 3 states were used to identify where bird abundance was associated with economic loss, but only survey responses collected from these 10 counties were used to generate the bird damage estimates included in the IMPLAN analysis.

\section{RESULTS AND DISCUSSION}

\section{Bird Use of Dairies}

Bird use of dairies varied seasonally (Table 2). Rank estimates of bird abundance, feed consumption, and bird fecal contamination of dairies were all greatest from January 1 to March 31 and least from July 1 to September 30. Among bird species reported on dairies, European starlings were the most common and destructive species (Table 3 ).

The reason for seasonal differences in bird use of dairies is well established in the literature. Seasonal increases are due to flocking and feeding behaviors exhibited by starlings and blackbird species during the late fall, winter, and early spring (Besser et al., 1968; Twedt and Glahn, 1982). Starlings, in particular, will use livestock facilities for food resources when other natural foods, such as insects, are limited (Dolbeer et al., 1978). During the summer, starling damage in dairies is minimal because insects are plentiful and birds have dispersed to rear young (Linz et al., 2007; Carlson et al., 2011b). Thus, large foraging flocks of starlings create a serious problem for dairies because the ubiquitous and highly nutritious cattle feed supplies are essential resources for overwintering starlings, making it incredibly difficult to repel them from using dairies.

\section{Feed Loss Data}

Cost per cwt differed by bird abundance categories $\left(F_{3,277}=3.98, P=0.008\right.$; Figure 1$)$. Dairies reporting zero birds spent $\$ 4.92(95 \% \mathrm{CI}=4.26,5.58)$ per cwt of 
Table 2. Seasonal mean rank estimates of bird damage to commercial dairies within Pennsylvania, New York, and Wisconsin in 2009

\begin{tabular}{lccc}
\hline $\begin{array}{l}\text { Seasonal bird } \\
\text { damage estimate }\end{array}$ & Mean $^{1}$ & SE & Count $^{2}(\overline{\mathrm{n}})$ \\
\hline Ranked bird abundance & & & \\
$\quad$ Jan 1 to Mar 31 & 1.54 & 0.07 & 216 \\
Apr 1 to Jun 30 & 2.42 & 0.07 & 203 \\
Jul 1 to Sep 30 & 2.59 & 0.08 & 204 \\
$\quad$ Oct 1 to Dec 31 & 1.75 & 0.06 & 208 \\
Ranked feed consumption & & & \\
Jan 1 to Mar 31 & 1.47 & 0.07 & 174 \\
Apr 1 to Jun 30 & 2.34 & 0.08 & 155 \\
Jul 1 to Sep 30 & 2.64 & 0.09 & 155 \\
Oct 1 to Dec 31 & 1.71 & 0.06 & 173 \\
Ranked fecal pollution & & & \\
Jan 1 to Mar 31 & 1.87 & 0.09 & 194 \\
Apr 1 to Jun 30 & 2.59 & 0.08 & 188 \\
Jul 1 to Sep 30 & 2.72 & 0.09 & 187 \\
Oct 1 to Dec 31 & 2.13 & 0.07 & 191 \\
\hline
\end{tabular}

${ }^{1}$ Ranked values, averaged from producer responses, ranged from 1 to 4 ( 1 = highest rank, 4 = lowest rank).

${ }^{2}$ Count data include only facilities documenting bird damage and denotes the number of survey responses used to estimate mean rank values per category.

milk produced, dairies reporting 1 to 1,000 birds spent $\$ 5.09(95 \% \mathrm{CI}=4.02,6.15)$ per cwt of milk produced, dairies reporting 1,001 to 10,000 birds spent $\$ 5.89(95 \%$ $\mathrm{CI}=4.61,7.18$ ) per cwt of milk produced, and dairies reporting more than 10,000 birds spent $\$ 6.99$ (95\% CI $=4.59,9.40)$ per cwt of milk produced in 2009. Among dairy operations reporting bird damage, the annual cost of feed loss to birds differed by bird abundance categories $\left(F_{3,236}=19.89, P<0.001\right.$; Figure 2$)$. Dairies reporting 1 to 1,000 birds lost $\$ 9,399.14$ (95\% CI $=$ $5,170.72,13,627.55)$ of cattle feed to bird damage, dairies reporting 1,001 to 10,000 lost $\$ 22,794.26$ (95\% CI $=$ $11,942.08,33,646.43)$ of cattle feed to bird damage, and dairies reporting more than 10,000 birds lost $\$ 64,401.51$ $(95 \%$ CI $=1,381.18,127,421.82)$ of cattle feed to bird damage.

Among dairy operations reporting bird damage, feed spoilage was associated with bird abundance estimates $\left(F_{2,214}=9.00, P<0.001 ;\right.$ Figure 3$)$. Dairies reporting 1 to 1,000 birds lost $4.2 \%(95 \% \mathrm{CI}=2.8 \%, 5.7 \%)$ to spoilage, dairies reporting 1,001 to 10,000 birds lost $5.2 \%(95 \% \mathrm{CI}=4.1 \%, 6.2 \%)$ to spoilage, and dairies reporting more than 10,000 birds lost $9.3 \%$ (95\% CI = $5.3 \%, 13.3 \%$ ) of their cattle feed to spoilage.

Among dairy operations reporting bird damage, feed loss to birds was associated with our bird abundance estimates $\left(F_{2,147}=10.95, P \leq 0.001 ;\right.$ Figure 4$)$. Dairies reporting 1 to 1,000 birds lost $2.8 \%(95 \% \mathrm{CI}=2.2 \%$, $3.3 \%$ ) to bird consumption, dairies reporting 1,001 to 10,000 birds lost $5.5 \%(95 \% \mathrm{CI}=4.2 \%, 6.8 \%)$ to consumption, and dairies reporting more than 10,000 birds
Table 3. Rank estimates of bird species observed and bird species causing damage to commercial dairies within Pennsylvania, New York, and Wisconsin in 2009

\begin{tabular}{lccc}
\hline Ranked bird species & Mean $^{1}$ & SE & Count $^{2}(\overline{\mathrm{n}})$ \\
\hline Bird species observed & & & \\
European starlings & 1.66 & 0.09 & 331 \\
House sparrow & 2.41 & 0.08 & 283 \\
Rock pigeon & 2.71 & 0.09 & 275 \\
American crow & 3.87 & 0.15 & 158 \\
Brown headed cowbird & 4.02 & 0.16 & 138 \\
Red-winged blackbird & 4.50 & 0.18 & 127 \\
Unknown & 4.71 & 0.43 & 28 \\
Birds causing damage & & & \\
European starlings & 1.56 & 0.08 & 312 \\
House sparrow & 2.54 & 0.10 & 227 \\
Rock pigeon & 2.61 & 0.10 & 227 \\
American crow & 3.77 & 0.18 & 122 \\
Brown headed cowbird & 4.25 & 0.20 & 105 \\
Red-winged blackbird & 4.59 & 0.22 & 98 \\
Unknown & 4.75 & 0.45 & 24 \\
\hline
\end{tabular}

${ }^{1}$ Ranked values, averaged from producer responses, ranged from 1 to 8 ( 1 = highest rank, $8=$ lowest rank $)$.

${ }^{2}$ Count data denote the number of surveys identifying species observed or causing damage.

lost $4.9 \%(95 \% \mathrm{CI}=1.6 \%, 8.2 \%)$ of their cattle feed to bird consumption.

Our survey results suggest that cattle feed costs increase as bird numbers increase, and this is due to the consumption and spoilage of cattle feed by birds. These are not the first data to show that bird damage increases feeding costs for livestock producers. Depenbusch et al. (2011) estimated that feed consumption by European starlings increases the daily production

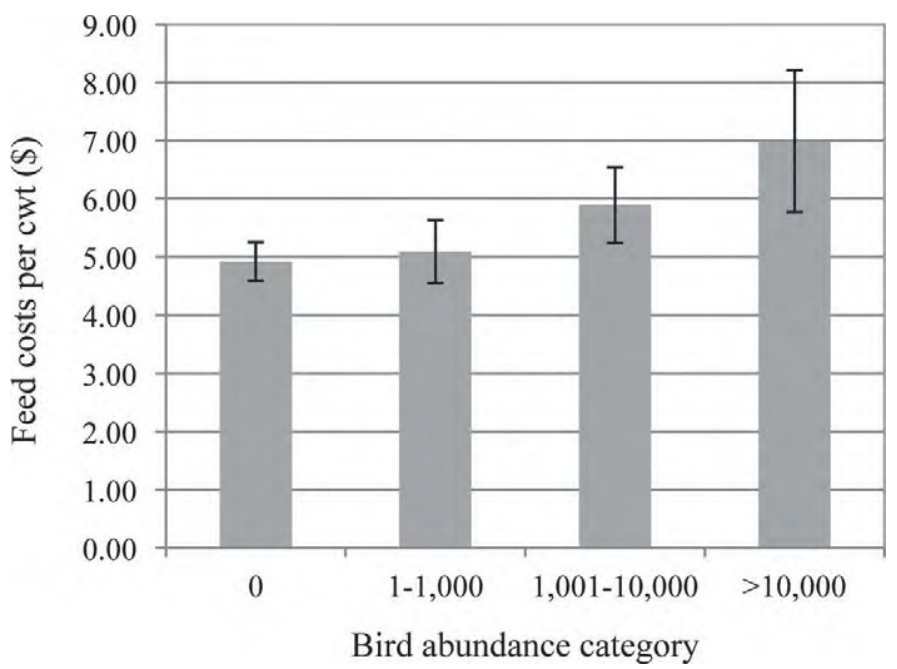

Figure 1. Weighted means and standard error estimates of cost per hundredweight (cwt) produced on dairies by bird abundance category. Data were collected from dairies within Pennsylvania, New York, and Wisconsin. Cost estimates reflect the annual cost per cow per year in 2009 . 


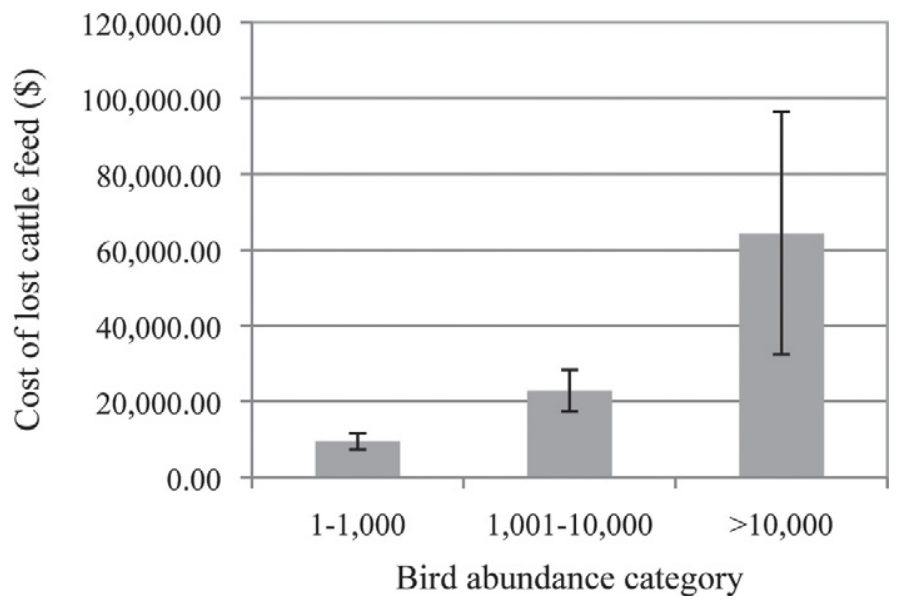

Figure 2. Weighted means and standard error estimates of production costs from cattle feed lost to birds by bird abundance category. Data were collected from dairies within Pennsylvania, New York, and Wisconsin. Cost estimates reflect the annual cost to producers in 2009.

cost by $\$ 0.92$ per feeder cow. Because access to feed supplies attracts birds to livestock facilities (Dolbeer et al., 1978; Feare et al., 1992; Linz et al., 2007), we conclude that reducing bird access to cattle feed and water would be one of the most effective ways to reduce bird use of dairies. This is best achieved through the targeted control of invasive birds while excluding native birds from cattle feed and water supplies.

\section{Herd Health Data}

On the basis of regression coefficients, veterinary care costs were not associated with bird abundance estimates $\left(F_{3,302}=1.38, P=0.2467 ;\right.$ Figure 5$)$, but facility size

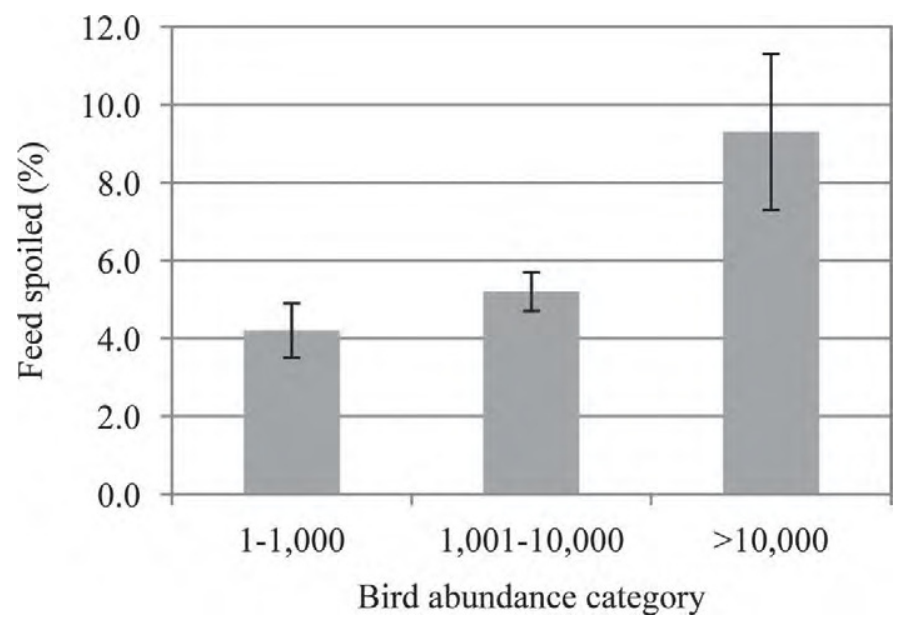

Figure 3. Weighted means and standard error estimates of percentage of cattle feed spoiled on dairies by bird abundance category. Data was collected from dairies within Pennsylvania, New York, and Wisconsin in 2009.

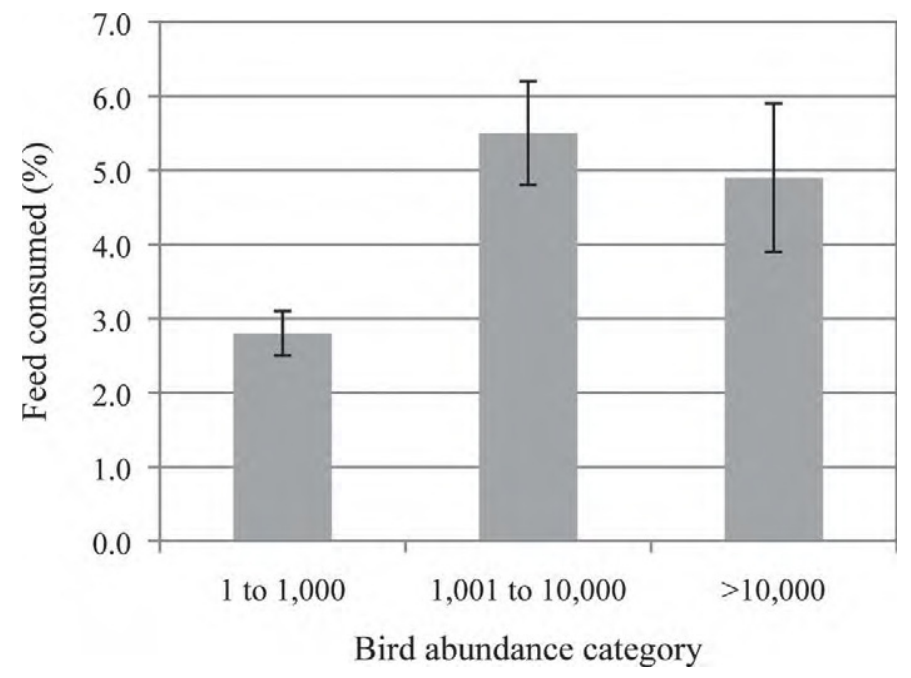

Figure 4. Weighted means and standard error estimates of percentage of cattle feed consumed by birds on dairies by bird abundance category. Data were collected from dairies within Pennsylvania, New York, and Wisconsin in 2009.

was significantly associated with increasing veterinary care costs $\left(F_{1,304}=9.30, P=0.0025\right)$. Dairies reporting zero birds spent $\$ 66.82(95 \% \mathrm{CI}=53.14,80.50)$ per cow per year on veterinary care. Dairies reporting 1 to 1,000 birds spent $\$ 80.00(95 \% \mathrm{CI}=63.45,96.55)$ per cow per year on veterinary care. Dairies reporting 1,001 to 10,000 birds spent $\$ 91.21$ (95\% CI $=69.65$, 112.77 ) per cow per year on veterinary care, and dairies reporting more than 10,000 birds spent $\$ 71.97$ (95\% CI $=36.81,107.11)$ per cow per year on veterinary care.

Bird abundance estimates were associated with the number of dairies self-reporting Salmonella spp. in their herd $\left(\chi_{3}^{2}=15.07, P<0.001\right)$. The association of predicted probabilities and observed responses was $54 \%$. Within this model, the probability of dairies reporting Salmonella spp. increased as bird abundance increased (Figure 6). On the basis of Wald confidence intervals for OR analyses, self-reporting of Salmonella spp. was lower in dairies reporting zero birds compared with dairies reporting $>10,000$ birds $(\mathrm{OR}=0.029,95 \% \mathrm{CI}$ $=0.004,0.202$ ). The odds of reporting Salmonella spp. were not lower in dairies reporting 1 to 1,000 birds compared with dairies reporting $>10,000$ birds (OR $=0.423,95 \% \mathrm{CI}=0.099,1.813)$ or dairies reporting 1,001 to 10,000 birds compared with dairies reporting $>10,000$ birds $(\mathrm{OR}=0.482,95 \% \mathrm{CI}=0.113,2.047)$.

Bird abundance estimates were associated with the number of dairies self-reporting MAP in their herds $\left(\chi_{3}^{2}=23.28, P<0.001 ;\right.$ Figure 7$)$. The association of predicted probabilities and observed responses was $41 \%$. Within this model, the probability of dairies reporting MAP increased as bird abundance increased. 


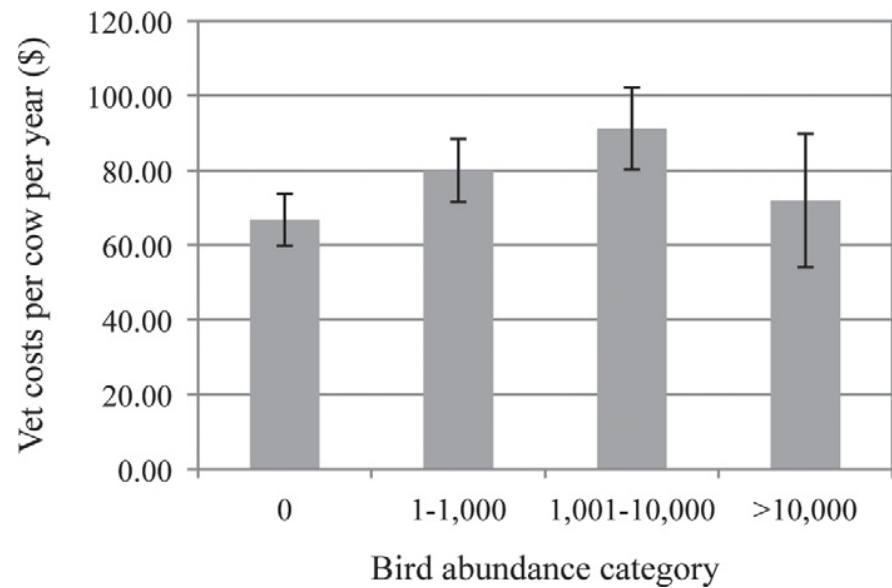

Figure 5. Weighted means and standard error estimates of veterinary care costs, per cow per year, on dairies by bird abundance category. Data were collected from dairies within Pennsylvania, New York, and Wisconsin in 2009. Cost estimates reflect the annual cost per cow per year in 2009 .

On the basis of Wald confidence intervals for OR analyses, self-reporting of MAP was lower in dairies reporting zero birds compared with dairies reporting $>10,000$ birds $(\mathrm{OR}=0.079,95 \% \mathrm{CI}=0.015,0.410)$. The odds of reporting MAP were not lower in dairies reporting 1 to 1,000 birds compared with dairies reporting $>10,000$ birds $(\mathrm{OR}=0.610,95 \% \mathrm{CI}=0.131,2.843)$ or dairies reporting 1,001 to 10,000 birds compared with dairies reporting $>10,000$ birds $(\mathrm{OR}=0.982,95 \% \mathrm{CI}=0.205$, 4.705).

Bird abundance estimates were not associated with veterinary costs when facility size was included as a model covariate, but bird abundance estimates were significant when simple main effects models, excluding

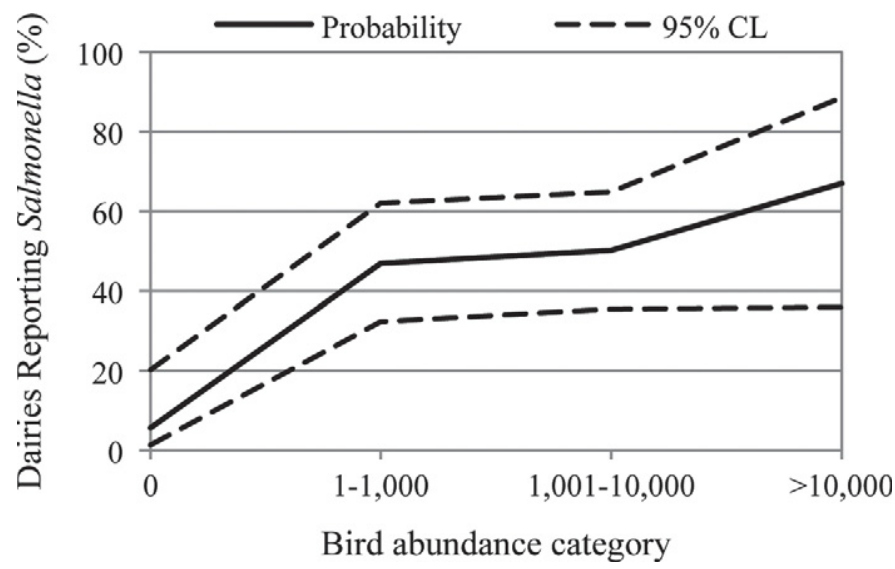

Figure 6. Predicted probability of commercial dairies self-reporting Salmonella spp. in their herds as a function of bird abundance category. Data were collected from survey responses submitted to dairy operations within Pennsylvania, New York, and Wisconsin in 2009.

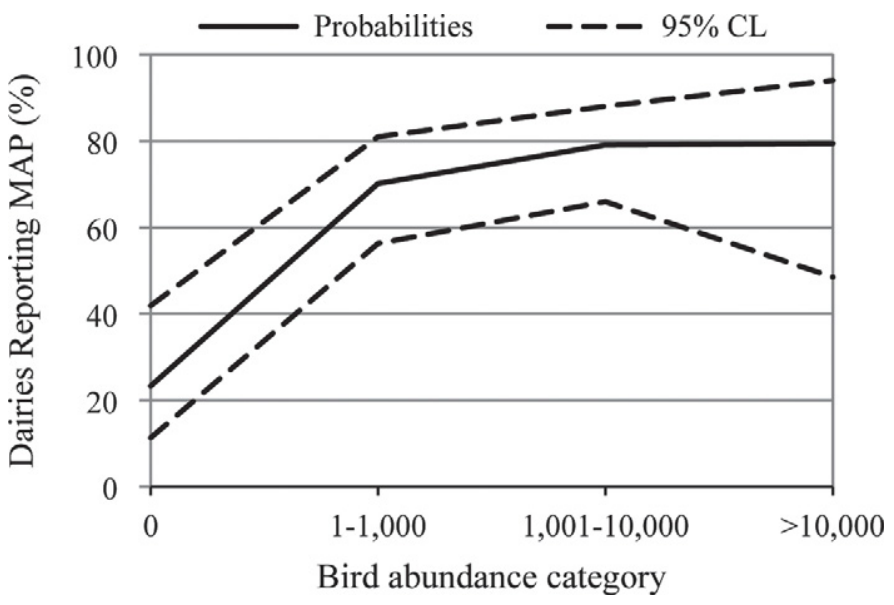

Figure 7. Predicted probability of commercial dairies self-reporting Mycobacterium avium ssp. paratuberculosis (MAP) in their herds as a function of bird abundance category. Data were collected from survey responses submitted to dairy operations within Pennsylvania, New York, and Wisconsin in 2009. CL = confidence limit.

facility size, were considered $\left(F_{3,302}=3.87, P=0.010\right)$. Considering the fact that the likelihood of dairies selfreporting Salmonella spp. and MAP increased as bird abundance increased, the veterinary cost data came as a bit of a surprise. Likely these results are because facility size was a better explanatory variable for increasing veterinary care costs than were our bird abundance estimates. Thus, the effect of facility size may have confounded our attempts to determine whether increasing veterinary care costs are associated with bird use of dairies.

We assert it is possible that bird damage may create veterinary health problems that lead to increased operating costs in dairies, based on the fact that the 3 most common and destructive bird species reported on this survey (the European starling, house sparrow, and rock pigeon) have previously been implicated as potential sources of bacterial contamination in dairies (Kirk et al., 2002; Pedersen et al., 2006; Williams et al., 2011). Starlings have also been implicated in the contamination of feedlots. The contamination of cattle feed and water with $S$. enterica is associated with the numbers of starlings on feedlots (Carlson et al., 2011b). The length of exposure to feedlot rations is associated with $S$. enterica fecal shedding by cattle (Fedorka-Cray et al., 1998), and starling control was shown to reduce $S$. enterica contamination of cattle feed and water within feedlots (Carlson et al., 2011a). This information suggests birds vector bacteria within feedlots, which contributes to infections within herds.

Our data suggest that birds vector bacteria in dairies in a manner that is similar to what is known to occur in feedlots. Bird use of dairies was associated 
with an increasing likelihood of dairies self-reporting Salmonella spp. and MAP. Bird feces are common in dairy rations, and starling feces have been shown to contain both $S$. enterica and MAP (Corn et al., 2005; Pedersen et al., 2006; Carlson et al., 2009). Thus, it is likely that bird use of dairies contributes to subclinical and clinical infections in the herd. More work must be done to adequately determine whether veterinary care costs and public health risks are created by bird use of dairies. We recommend, based on previous publications and our own Salmonella spp. and MAP data, that additional studies be conducted to determine whether veterinary costs increase as a consequence of bird damage in dairies.

\section{Bird Effects on Dairy Production}

No significant associations were observed between dairy production and bird abundance estimates. The amount of milk produced by dairies was not associated with bird abundance $\left(F_{3,294}=2.02, P=0.111\right)$, but facility size was significantly associated with increasing milk production $\left(F_{1,296}=13.22, P<0.001\right)$. Data on the square root-transformed percentage of protein within milk were not associated with bird abundance $\left(F_{3,367}=1.60, P=0.189\right)$, nor was facility size $\left(F_{1,369}\right.$ $=2.01, P=0.157)$.

Our survey results suggest milk production was not affected by bird damage. This is not the first attempt to document production losses. Glahn and Stone (1984) showed that cattle and pig exposure to starling excrement did not adversely affect $\mathrm{BW}$ gain or feed conversion efficiency. Other data suggest that feedlots will push more feed to cattle to compensate for losses caused by bird damage (Depenbusch et al., 2011). Nutritional intake by dairy cattle will be affected by bird consumption only if the sourcing of feed by birds occurs after the diet is offered to cattle. Birds sourcing feed from storage bunkers and feed piles will contribute to an economic loss, but it will not alter the nutritional quality of feed offered to dairy cattle. Currently, data examining the nutritional effects within feed bunks do not exist for dairies. This information could be collected with field studies or controlled experiments with birds housed in aviaries. In addition, novel experimental infection studies should be developed to better assess whether microbial contamination of cattle feed and water supplies by birds could reduce milk and butterfat production in dairies.

\section{Bird Control Strategies}

Bird control strategies differed in terms of their effectiveness (Table 4). Operational control conducted by Wildlife Services biologists received the highest "very effective" rating (35\%), and chemical repellents received the lowest "very effective" rating among all the methods assessed. Shooting received the highest "moderately effective" rating (64\%) and the lowest "not effective" rating (17\%) among all the methods assessed. The average annual cost for bird control differed substantially by method. Bird netting was the most expensive $(\$ 1,229.76)$, and live trapping was the least expensive (\$93.85) among all of the methods assessed.

Survey data suggest that Wildlife Services operational control programs may have additional benefits that have previously been overlooked. The top 3 most common and destructive bird species (European starlings, house sparrows, and rock pigeons) reported by dairy operators are all invasive to North America and are excluded from protections under the Migratory Bird Treaty Act. This provides wildlife managers and the dairy industry a unique opportunity. Bird control on dairies that effectively targets invasive species can combat a source of both environmental and economic damage. Dairy operators and state and federal wildlife management agencies can partner in cooperative service agreements to reduce bird damage on dairy

Table 4. Efficacy and average cost of control strategies used to reduce bird damage on commercial dairies within Pennsylvania, New York, and Wisconsin in 2009

\begin{tabular}{|c|c|c|c|c|}
\hline \multirow[b]{2}{*}{ Bird control strategy } & \multicolumn{3}{|c|}{ Effectiveness of control strategy (\%) } & \multirow{2}{*}{$\begin{array}{l}\text { Average annual } \\
\text { cost }(\$)\end{array}$} \\
\hline & Very & Moderate & Not & \\
\hline Wildlife Services & 35 & 22 & 43 & 719.56 \\
\hline Starlicide Complete $^{1}$ & 15 & 33 & 52 & 660.00 \\
\hline Chemical repellents & 7 & 21 & 71 & 595.56 \\
\hline Shooting & 17 & 64 & 19 & 153.24 \\
\hline Live trapping & 10 & 30 & 60 & 93.85 \\
\hline Netting or birdproofing & 23 & 44 & 33 & $1,229.76$ \\
\hline Habitat modification & 11 & 32 & 57 & 288.75 \\
\hline Other $^{2}$ & 24 & 44 & 32 & 562.14 \\
\hline
\end{tabular}


operations. If implemented effectively, this approach may dramatically improve on current efforts to manage invasive bird species causing damage in North America. Thus, improved coordination between these stakeholders may help reduce the economic damage to dairies while reducing the environmental damage caused by invasive bird species.

Nonlethal control of birds on dairies will be difficult to implement. Food and water are essential resources, and the attraction by birds will continue to be very strong. This probably explains why live trapping and chemical repellents were not viewed as being as effective as lethal control or exclusionary devices. Thus, we conclude that in the absence of alternate food resources, most hazing and repellent devices will lack the efficacy necessary to dissuade bird use of dairies.

Netting was the only nonlethal control strategy shown to be moderately effective at controlling birds on dairies. Annual cost estimates for netting were higher than for any other method reported by dairy operators, suggesting that current use may not be cost effective. Netting differs from other nonlethal control by physically excluding birds from accessing dairy rations. When no holes or gaps are present, netting will be $100 \%$ effective at excluding birds from the protected area. Unfortunately, this is rarely the case because of the logistical difficulty of effectively excluding birds from cattle feed while still allowing access to farm machinery and cattle, which likely explains why netting was reported as only a moderately effective bird control tool in dairies. Because netting is the only nonlethal form of bird control that shows promise as an effective deterrent, it is important to improve its efficacy while reducing the cost so this tool can adequately accommodate the needs of dairies.

\section{Animal Housing Data}

The method of animal penning was associated with bird abundance categories $\left(\chi_{2}^{2}=45.74, P<0.001\right)$. Specifically, dairies that used tie stalls were 5.5 times more likely to have birds recorded in the lowest bird abundance category (zero birds) compared with dairies using free stalls $(\mathrm{OR}=5.503,95 \% \mathrm{CI}=3.272,9.256)$. Dairies group housing cattle in paddocks did not have bird abundances that differed from those of facilities using free stalls or tie stalls.

Free stalls are typically found on larger facilities with open-curtain barns, and they have feed sources readily accessible to foraging flocks of birds. Tie stalls are typically found on older, smaller facilities with closed-door barns where feed is less accessible. We conclude that the difference in bird abundance estimates between facilities using free stalls compared with tie stalls has less to do with the size of facilities or the nature of penning and more to do with physical structures in the dairies that affect the ability of birds to access cattle feed supplies.

\section{IMPLAN Analysis}

Damage estimates included in the IMPLAN analysis were based on survey results, and we restricted our economic estimates to total feed losses (consumed plus spoilage estimates). All herd health and cost estimates were omitted from the IMPLAN analysis because these are preliminary findings that lack adequate, independent corroboration. Survey results indicated that an average of $6.3 \%$ of cattle feed was lost to birds on dairies in Pennsylvania in 2009; high and low feed loss estimates for the 10 counties were 7.18 and $2.44 \%$. We used National Agricultural Statistical Service databases to determine the number of dairy cows within each county included in the IMPLAN analysis. Feed costs per cow per year (\$963) for Pennsylvania dairies were estimated from our survey data. The total feed cost in each county was determined by multiplying the total number of cows by our survey estimates of feed costs per cow per year. We calculated the cost of lost feed by multiplying the estimated total feed cost by the amount of feed lost to birds $6.3 \%$ (0.063). These feed loss estimates were used as inputs in the IMPLAN model to estimate state-wide economic losses. Modeling the opportunity costs of the low, mean, and high estimates of feed loss to birds indicated that between $\$ 4.11$ and $\$ 12.08$ million (mean $\$ 10.6$ million) in total economic damage occurred, with approximately 43 to 128 jobs (mean 112) forgone statewide in 2009.

The IMPLAN portion of the analysis is not to suggest with certainty that the producer and the economy suffered these losses and individuals were out of jobs. Many producers acknowledge that they lose feed to birds and that is simply "the cost of doing business." The importance of this analysis is then to provide the first estimates of what that cost may be in terms of revenue and jobs. Producers have lived with this damage as part of the production process; however, dollar estimates of what this damage may allow producers and governments to make informed decisions regarding the management of birds at dairy facilities. In the absence of monetizing these effects, producers may be living with an economically inefficient level of bird damage.

The simulated economic impacts projected by the IO model have limitations and suffer from the general weaknesses of all deterministic models. This is a static model in that the economic impact of damage by birds 
results in a unidirectional immediate change in all other sectors affected by this loss. This may not be the case in a more dynamic model setting.

\section{CONCLUSIONS}

In conclusion, this assessment of bird damage in dairies and the accompanying IMPLAN analysis are a first attempt at identifying offending bird species, the scope of the damage, the efficacy of management options, and future research needs. It should not be viewed as a definitive assessment of bird damage and associated economic impacts in commercial dairies. We recommend that researchers design controlled experiments to determine how bird consumption of cattle rations affects the nutritional quality of feed. In addition, experimental infection studies and ecological field studies should be conducted to assess the relationship between high-risk bird species and microorganisms pathogenic to cattle and people. We recommend that dairies experiencing bird damage focus on controlling invasive bird species with the assistance of professional wildlife managers while advocating for research organizations to improve on nonlethal bird management strategies. Last, management of bird damage should be based on whether a proposed action is cost effective. Additional research needs to be conducted to better assess the economics of managing wildlife damage in dairies. This information will help dairies make better informed economic decisions and identify where veterinary and public health risks are created as a result of bird use of dairies.

\section{REFERENCES}

Besser, J. F., J. W. DeGrazio, and J. L. Guarino. 1968. Cost of wintering starlings and red-winged blackbirds at feedlots. J. Wildl. Manage. 32:179-180.

Carlson, J. C., L. Clark, M. F. Antolin, and M. D. Salman. 2009. Rock pigeon use of livestock facilities in northern Colorado: Implications for improving farm bio-security. Hum.-Wildl. Interact. 5:112-122.

Carlson, J. C., R. M. Engeman, D. R. Hyatt, R. L. Gilliland, T. J. DeLiberto, L. Clark, M. J. Bodenchuk, and G. M. Linz. 2011a. Efficacy of European starling control to reduce Salmonella enterica contamination in a concentrated animal feeding operation in the Texas panhandle. BMC Vet. Res. 7:9.

Carlson, J. C., A. B. Franklin, D. R. Hyatt, S. E. Pettit, and G. M. Linz. 2011b. The role of starlings in the spread of Salmonella within concentrated animal feeding operations. J. Appl. Ecol. 2:479-486.

Corn, J. L., E. J. B. Manning, S. Sreevatsan, and J. R. Fisher. 2005. Isolation of Mycobacterium avium ssp. paratuberculosis from freeranging birds and mammals on livestock premises. Appl. Environ. Microbiol. 71:6963-6967.
Depenbusch, B. E., J. S. Drouillard, and C. D. Lee. 2011. Feed depredation by European starlings in a Kansas feedlot. Hum.-Wildl. Interact. 5:58-65.

Dolbeer, R. A., P. A. Wornecki, J. R. Strickley, and S. B. White. 1978. Agricultural impact of a winter population of blackbirds and starlings. Wilson Bull. 90:31-44.

Feare, C. J. 1984. The Starling. Oxford University Press, Oxford, NY.

Feare, C. J., P. Douville de Franssu, and S. J. Peris. 1992. The starling in Europe: Multiple approaches to a problem species. Pages 83-88 in Proc. 15th Vertebr. Pest Conf., Sacramento, CA. University of California, Davis.

Fedorka-Cray, P. J., D. A. Dargetz, L. A. Thomas, and J. T. Gray. 1998. Survey of Salmonella serotypes in feedlot cattle. J. Food Prot. 61:525-530.

Glahn, J. F., and D. L. Otis. 1981. Approach for assessing feed loss damage by starlings at livestock feedlots. ASTM Special Tech. Publ. No.752. American Society for Testing and Materials, West Conshohocken, PA.

Glahn, J. F., and W. Stone. 1984. Effects of starling excrement in the food of cattle and pigs. Anim. Prod. 38:439-446.

Hubálek, Z. 2004. An annotated checklist of pathogenic microorganisms associated with migratory birds. J. Wildl. Dis. 40:639-659.

Kirk, J. H., C. A. Holmberg, and J. S. Jeffrey. 2002. Prevalence of Salmonella spp. in selected birds captured on California dairies. J. Am. Vet. Med. Assoc. 220:359-362.

Lee, C. 1987. Results of a bird damage survey of Kansas feedlots. Pages 225-227 in Proc. Great Plains Wildlife Damage Control Workshop, Univ. Nebraska, Lincoln. General Technical Report RM-154. US Department of Agriculture Forest Service, Washington, DC.

LeJeune, J., H. J. Homan, G. M. Linz, and D. L. Pearl. 2008. Role of the European starling in the transmission of E. coli O157 on dairy farms. Pages 31-33 in Proc. 23rd Vertebr. Pest Conf., San Diego, CA. University of California, Davis.

Linz, G. M., H. J. Homan, S. M. Gaukler, L. B. Penry, and W. J. Bleier. 2007. European starlings: A review of an invasive species with far-reaching impacts. Page 378-386 in Managing Vertebrate Invasive Species: Proc. Int. Symp. US Dept. Agric./Anim. Plant Health Insp. Serv./Wildl. Serv., Natl. Wildl. Res. Cent., Fort Collins, CO.

Pedersen, K., and L. Clark. 2007. A review of Shiga toxin Escherichia coli and Salmonella enterica in cattle and free-ranging birds: Potential association and epidemiological links. Hum.-Wildl. Confl. 1:68-77.

Pedersen, K., L. Clark, W. F. Andelt, and M. D. Salman. 2006. Prevalence of shiga toxin-producing Escherica coli and Salmonella enterica in rock pigeons captured in Fort Collins, Colorado. J. Wildl. Dis. $42: 46-55$.

Pimentel, D., R. Zuniga, and D. Morrison. 2005. Update on the environmental and economic costs of alien-invasive species in the United States. Ecol. Econ. 52:273-288.

Twedt, D. J., and J. F. Glahn. 1982. Reducing starling depredation at livestock feeding operations through changes in management practices. Pages 159-163 in Proc. 10th Vertebr. Pest Conf., Monterey, CA. University of California, Davis.

White, S. B., R. A. Dolbeer, and T. A. Bookhout. 1985. Ecology, bioenergetics, and agricultural impacts of a winter-roosting population of blackbirds and starlings. Wildl. Monogr. 93:1-42.

Williams, M. L., D. L. Pearl, and J. T. LeJeune. 2011. Multiple-locus variable-nucleotide tandem repeat subtype analysis implicates European starlings as biological vectors for Escherichia coli O157:H7 in Ohio, USA. J. Appl. Microbiol. 111:982-988. 